\title{
FLORÍSTICA DE ALGUNAS PLANTAS MEDICINALES
}

\author{
FLORISTICS OF SOME MEDICINE PLANTS
}

Oswaldo Salaverry ${ }^{1,2, a}$, Jorge Cabrera ${ }^{1, b}$

\begin{abstract}
Las plantas medicinales han acompañado al ser humano desde la más remota antigüedad, no hay cultura que no haya desarrollado su propia flora medicinal, la cual es generalmente transmitida por tradición oral. Hasta hace unas cuantas décadas todavía el reconocimiento de estas plantas era parte del estudio médico y también de amplio conocimiento popular. La creciente urbanización y consiguiente alejamiento de las fuentes silvestres de plantas medicinales ha llevado a un creciente desconocimiento de su presentación natural. A pesar que la mayoría de personas cree poder reconocer una planta medicinal por la forma de sus hojas, su olor $u$ otras características, el reconocimiento específico de una planta solo es posible si se cuenta con sus órganos sexuales, es decir si se cuenta con su flor. Esta florística de las plantas medicinales es poco conocida a pesar que tendría un uso práctico al permitir reconocer con exactitud que estamos frente a la planta medicinal que buscamos y no frente a otra especie con similares características de sus hojas o tallos.
\end{abstract}

Una peculiaridad de las plantas medicinales es que algunas de ellas presentan flores de insólita belleza. En la siguiente selección mostramos algunas flores de plantas medicinales que destacan en algunos casos por su amplio uso y en otras por su variedad y diversidad de usos terapéuticos, pero al mismo tiempo tienen inflorescencias de particular y peculiar belleza. Todas las fotos corresponden a los jardines botánicos de plantas medicinales del Centro Nacional de Salud Intercultural (CENSI) del Instituto Nacional de Salud, en Lima, Perú. Estos jardines son únicos en su género en nuestro país pues conservan más de 500 distintas especies de plantas medicinales, la mayoría peruanas, permitiendo así que sus visitantes no solo conozcan más de las propiedades tradicionales de las plantas sino que también se deleiten con la rara belleza de sus flores.

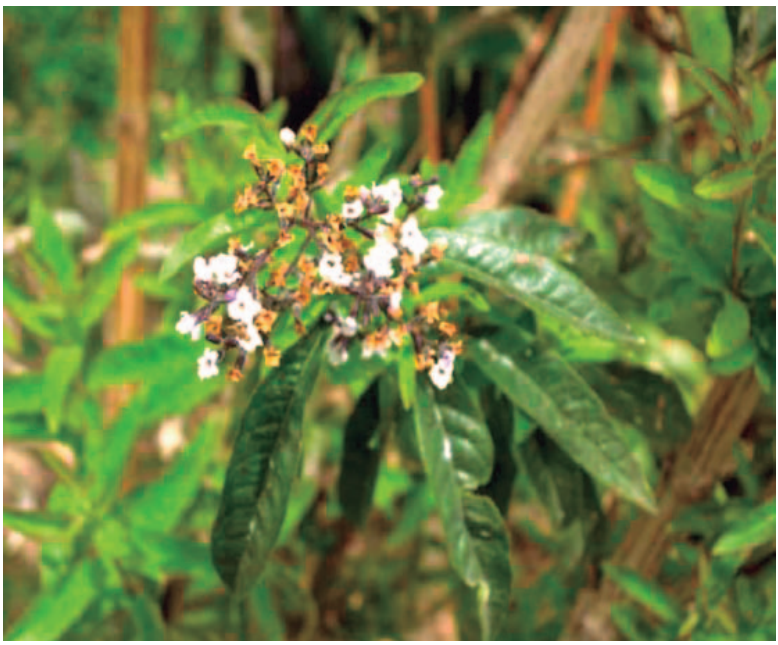

Figura 1. Cedrón (Aloysia citrodora Paláu)

CEDRÓN (Aloysia citrodora Paláu)

Arbusto nativo sudamericano (Figura 1), conocido también como verbena aromática (1), se introdujo en Europa desde el XVI. En la medicina popular es usado en forma de infusión como tónico estomacal y el tratamiento de indigestiones (2). En la medicina tradicional peruana se reportan usos más amplios, incluyendo afecciones respiratorias además de las gastrointestinales ${ }^{(3)}$. Científicamente se ha demostrado un efecto antioxidante ${ }^{(4)}$.

\section{AGUAYMANTO (Physalis peruviana L.)}

Planta nativa peruana (Figura 2), su fruto es conocido como uchuva en la amazonia y en inglés

\footnotetext{
Centro Nacional de Salud Intercultural, Instituto Nacional de Salud. Lima, Perú.

Facultad de Medicina, Universidad Nacional Mayor de San Marcos. Lima, Perú.

Médico, doctor en Medicina; ${ }^{b}$ bachiller en Biología

Recibido: 28-12-13 Aprobado: 12-02-14
}

Citar como: Salaverry O, Cabrera J. Florística de algunas plantas medicinales [galería]. Rev Peru Med Exp Salud Publica. 2014;31(1):165-8. 


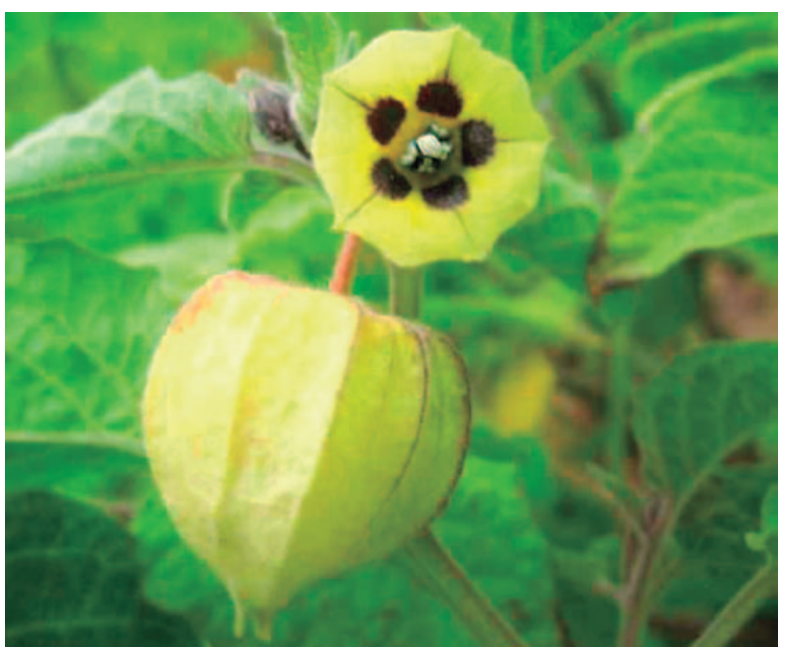

Figura 2. Aguaymanto (Physalis peruviana L.)

como goldenberry, pertenece a la misma familia (Solanaceas) que la papa y el tomate, se ha difundido en toda América y gran parte de África, donde se cultiva comercialmente. Además de su uso alimenticio se ha comprobado su efecto antioxidante ${ }^{(5)}$ y antitumoral en cáncer de pulmón ${ }^{(6)}$.

\section{ACHIOTE (Bixa orellana L.)}

Arbusto sudamericano (Figura 3) conocido por sus semillas que contienen el pigmento annato o bixina muy utilizado en la industria alimentaria. Sus usos tradicionales, muy amplios, incluyen desde el uso ritual de su colorante hasta el uso de las hojas por sus propiedades antimicrobianas y antifúngicas.

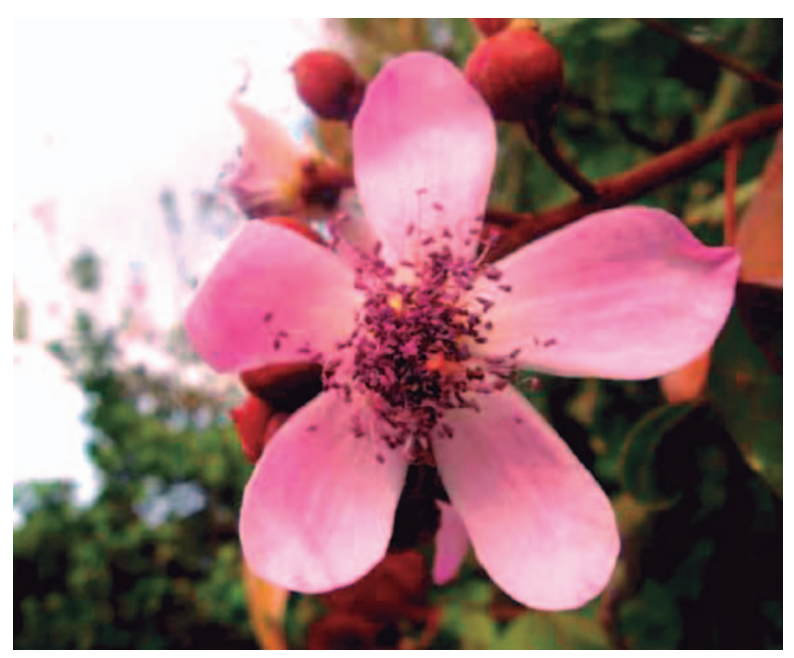

Figura 3. Achiote (Bixa orellana L.)

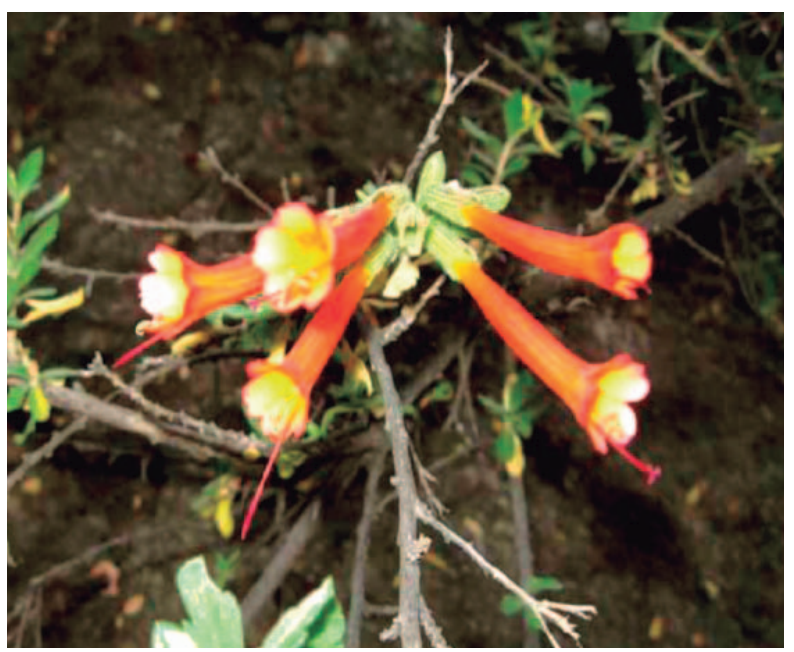

Figura 4. Cantuta (Cantua buxifolia Juss. ex Lam)

\section{CANTUTA (Cantua buxifolia Juss. ex Lam)}

Flor nacional del Perú (Figura 4), en la época incaica se consagraba al sol o Inti y por eso su amplia difusión. La inflorescencia era usada por la medicina popular contra la tos y para los ojos inflamados. El cocimiento de flores y ramas se utiliza contra la diarrea.

\section{YAWAR PIRI PIRI (Eleutherine bulbosa (Mill.) Urb)}

Usada tradicionalmente para problemas de fertilidad y enfermedades ginecológicas (Figura 5). Otros usos tradicionales lo incluyen como vulnerario, plantas que se usan en el tratamiento de heridas superficiales y úlceras. Se ha demostrado su efecto antibacteriano ${ }^{(7)}$ y antifúngico ${ }^{(8)}$.

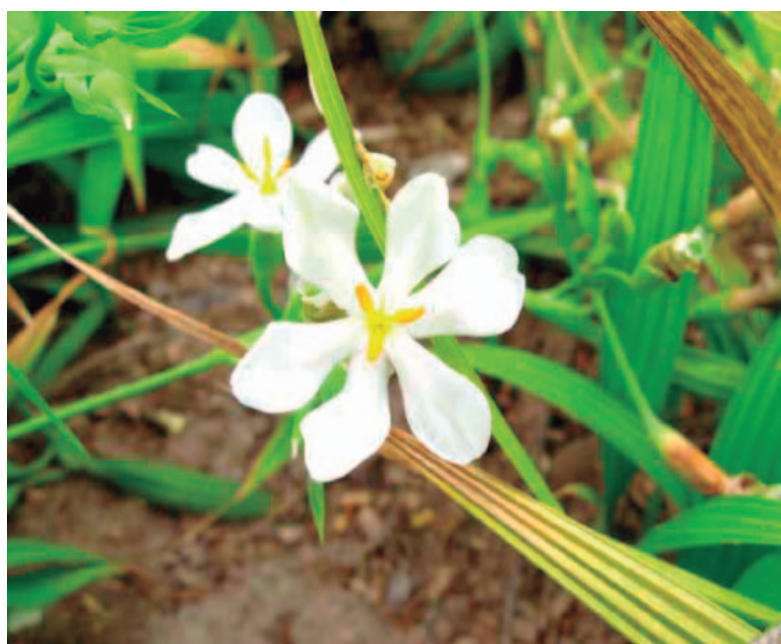

Figura 5. Yawar piri piri (Eleutherine bulbosa [Mill.] Urb) 


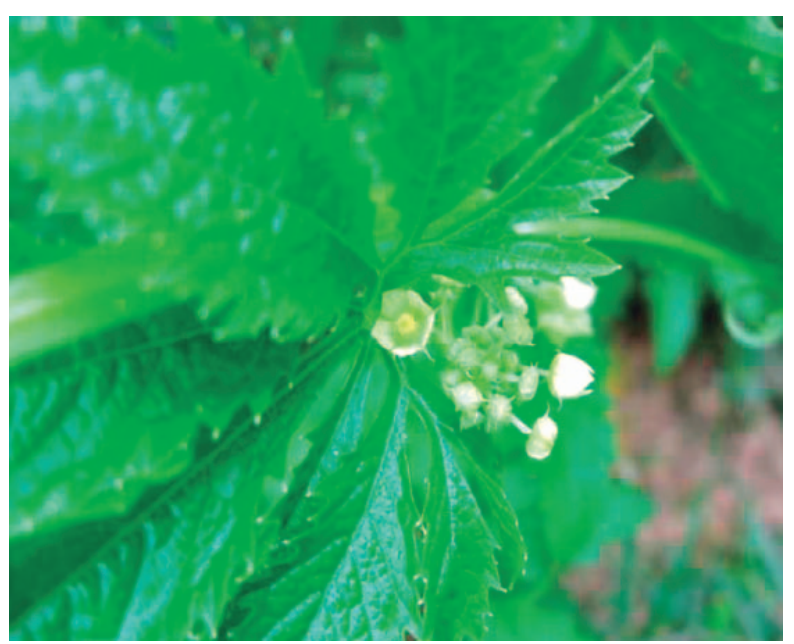

Figura 6. Caigua (Cyclanthera pedata (L.) Schrad)

\section{CAIGUA (Cyclanthera pedata (L.) Schrad)}

Planta trepadora (Figura 6) originaria de la costa peruana y difundida en la zona andina de toda Sudamérica; muy conocida por el uso alimenticio de su fruto, se reportan usos tradicionales para enfermedades hepáticas (9) y la diabetes. En medicina popular se la utiliza en dietas reductoras de peso y control de presión arterial.

\section{GUANÁBANA (Annona muricata)}

Árbol nativo del Perú (Figura 7), difundido en toda Sudamérica, su fruto conocido también como graviola, es ampliamente conocido (10). Tradicionalmente se utiliza sus hojas y corteza en muy diversas afecciones digestivas y respiratorias, en los últimos años se ha difundido un supuesto efecto anticancerígeno. No existen evidencias de dicho efecto en humanos aunque se reportan efectos antitumorales en pruebas animales.

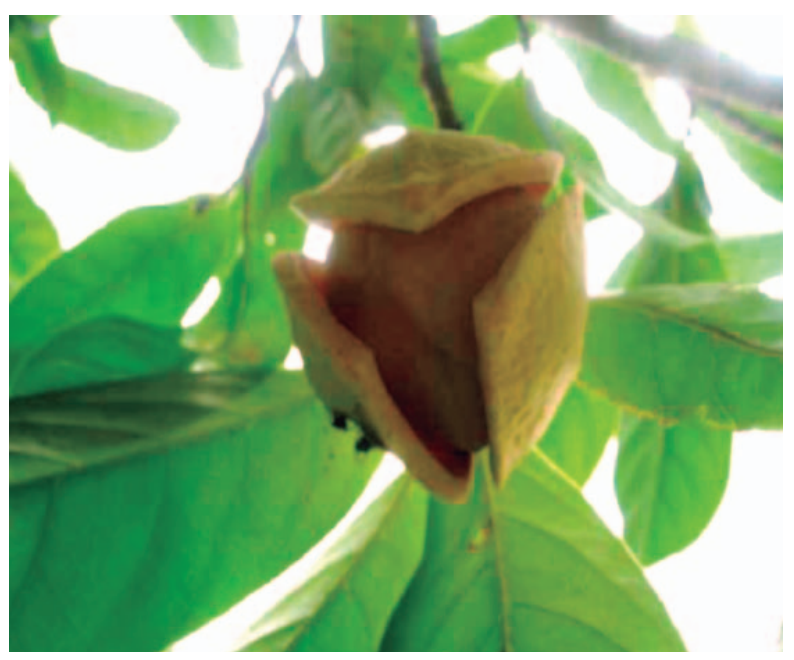

Figura 7. Guanábana (Annona muricata)

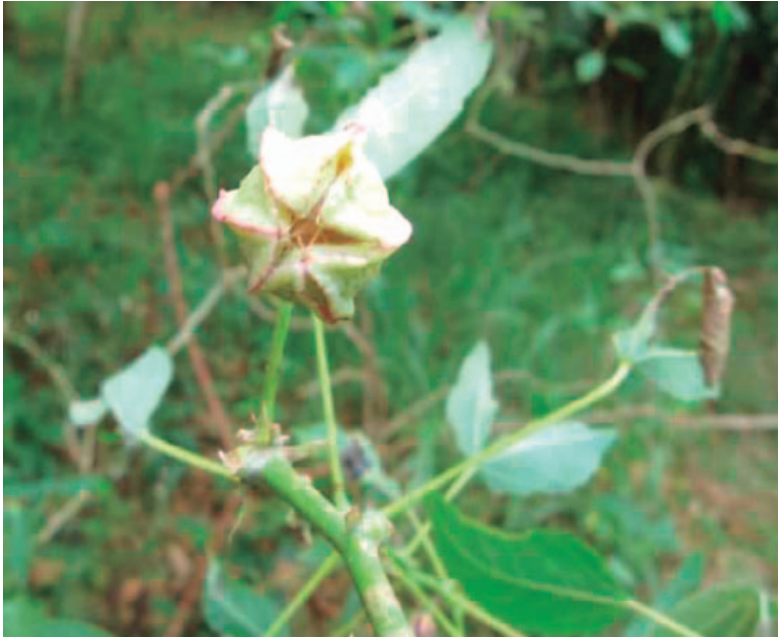

Figura 8. Yuca (Manihot esculenta Crantz)

YUCA (Manihot esculenta Crantz)

Arbusto sudamericano (Figura 8), cuya raíz, conocida también como mandioca, es ampliamente utilizada como alimento. Sus hojas se usan tradicionalmente para infecciones de la piel, prurito, quemaduras o enfermedades eruptivas ${ }^{(11)}$; otros usos lo incluyen como antiparasitario

\section{MARACUYA (Passiflora edulis Sims)}

Enredadera amazónica cuya compleja flor (Figura 9) ha dado lugar a diversas interpretaciones, incluso teológicas. Su fruto es utilizado como saborizante o para elaborar bebidas refrescantes; sus hojas desecadas se utilizan tradicionalmente "para los nervios" con un efecto tranquilizante o incluso hipnótico, también se reporta uso como antipirético y para problemas de la piel.

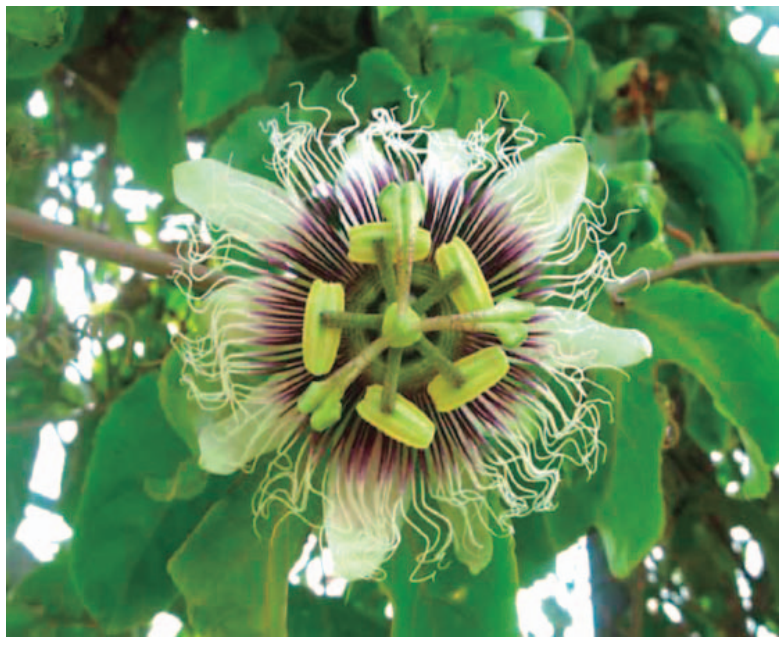

Figura 9. Maracuya (Passiflora edulis Sims) 


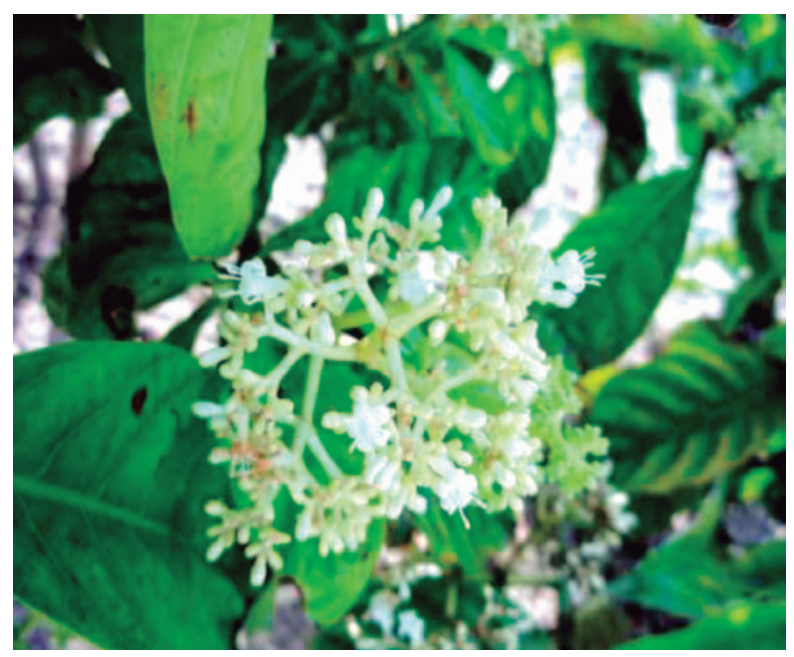

Figura 10. Chacruna (Psychotria viridis Ruiz \& Pav)

\section{CHACRUNA (Psychotria viridis Ruiz \& Pav)}

Planta originaria (Figura 10) de la Amazonia peruana se usa como purgante, pero su uso más difundido es en cocción conjunta con la Banisteriopsis caapi (ayahuasca) para elaborar el brebaje utilizado en el ritual de la ayahuasca. Sus propiedades psicoactivas limitan su automedicación en medicina tradicional, pudiendo ser utilizado solo por los sanadores tradicionales.

\section{REFERENCIAS BIBLIOGRÁFICAS}

1. Soukup J. Vocabulario de los nombres vulgares de la flora peruana y catálogo de los géneros. $2^{\circ}$ ed. Lima: Ed. Salesiana; 1979.

2. Ragone MI, Sella M, Conforti P, Volonté MG, Consolini AE. The spasmolytic effect of Aloysia citriodora Palau (South American cedrón) is partially due to its vitexin but not isovitexin on rat duodenums. J Ethnopharmacol. 2007;113(2):258-66.
3. Bourdy G, Valadeau C, Albán J, editores. Yato' Ramuesh: Plantas Medicinales Yanesha. Lima: Remanso Ediciones E.I.R.L.; 2008.

4. Carrera-Quintanar L, Funes L, Viudes E, Tur J, Micol V, Roche E, et al. Antioxidanta effect of lemon verbena extracts in lymphocytes of university students performing aerobic training program. Scand J Med Sci Sports. 2012;22(4):45461. doi: 10.1111/j.1600-0838.2010.01244.x.

5. Wu SJ, Ng LT, Huang YM, Lin DL, Wang SS, Huang SN, et al. Antioxidant activities of Physalis peruviana. Biol Pharm Bull. 2005; 28(6):963-6.

6. Yen CY, Chiu CC, Chang FR, Chen JY, Hwang CC, Hseu YC, et al. 4beta-Hydroxywithanolide E from Physalis peruviana (golden berry) inhibits growth of human lung cancer cells through DNA damage, apoptosis and G2/M arrest. BMC Cancer. 2010;10:46. doi: 10.1186/1471-2407-10-46.

7. Bianchi C, Ceriotti G. Chemical and pharmacological investigations of constituents of Eleutherinebulbosa (Miller) Urb.(Iridaceae). J Pharm Sci. 1975;64(8):1305-8.

8. Alves TM, Kloos H, Zani CL. Eleutherinone, a novel fungitoxic naphthoquinone from Eleutherine bulbosa (Iridaceae). Mem Inst Oswaldo Cruz. 2003;98(5):709-12.

9. Delgado HE. La Medicina Casera en Ayacucho. Ayacucho, Perú: Universidad Nacional de San Cristóbal de Huamanga; 1988.

10. Cabieses F. Apuntes de medicina tradicional. La racionalización de lo irracional. Tomo II. Lima. DISELPESA; 1993.

11. Mejía K, Rengifo E. Plantas Medicinales de Uso Popular en la Amazonia Peruana. 2 Ed. Lima: Proyecto Araucaria Amazonas Nauta, Asociación Gráfica Educativa; 2000
Correspondencia: Oswaldo Salaverry García

Dirección: Calle Cápac Yupanqui 1400, Lima 11, Perú. Teléfono: (511) 748-0000 Axo: 1345

Correo electrónico: oswaldosalaverry@gmail.com 